\title{
Integration of Information Systems for Predictive Workforce Analytics: Models, Synergy, Security of Entrepreneurship
}

\author{
Galyna O. Chornous ${ }^{1}$, Viktoriya L. Gura ${ }^{2}$
}

\begin{abstract}
The era of information economy leads to redesigning not only business models of organizations but also to rethinking the human resources paradigm to harness the power of state-of-the-art technology for Human Capital Management (HCM) optimization. Predictive analytics and computational intelligence will bring transformative change to HCM. This paper deals with issues of HCM optimization based on the models of predictive workforce analytics (WFA) and Business Intelligence (BI). The main trends in the implementation of predictive WFA in the world and in Ukraine, as well as the need to protect business data for security of entrepreneurship and the tasks of predictive analysis in the context of proactive HCM were examined. Some models of effective integration of information systems for predictive WFA were proposed, their advantages and disadvantages were analyzed. These models combine ERP, HCM, BI, Predictive Analytics, and security systems. As an example, integration of HCM system, the analytics platform (IBM SPSS Modeler), BI system (IBM Planning Analytics), and security platform (IBM QRadar Security Intelligence Platform) for predicting the employee attrition was shown. This integration provides a cycle 'prediction - planning - performance review - causal analysis' to support protected data-driven decision making in proactive HCM The results of the research support ensuring the effective management of all spectrum of risks associated with the collection, storage and use of data.
\end{abstract}

Keywords: Workforce Analytics (WFA), Human Capital Management (HCM), Predictive Analytics, Proactive Management, BI, Information Systems (IS), Integration, Security of Entrepreneurship

\section{Introduction}

The era of information economy leads to redesigning not only business models of organizations but also to rethinking the human resources (HR) paradigm to harness the power of state-of-the-art technology for Human Capital Management (HCM) optimization. Together with artificial intelligence, this needs highly skilled people to maximize the benefits of digitization. Human talent is the key factor linking innovation, competitiveness, and growth in the 21 st century. Digitization transforms how organizations make use of talent, helps them build power workforces, embrace flexible working, improve teaming, and analyze performance.

At the same time, such situation caused new challenges, e.g., cyber-risks and security threats of the entrepreneurship. Nowadays we can face with not honest entrepreneurs who provide illegal activities such as transfer of dual-use technologies and unauthorized use of information to weaken the positions of competitors.

${ }^{1}$ Dr. Sc. (Economics), Associate Professor, Department of Economic Cybernetics, Faculty of Economics, Taras Shevchenko National University of Kyiv, Ukraine

${ }^{2} \mathrm{PhD}$ (Economics), Associate Professor, Department of Entrepreneurship, Faculty of Economics, Taras Shevchenko National University of Kyiv, Ukraine 
Artificial intelligence opens new capabilities for HCM. Analytics tools are intelligently selecting candidates, and coaching managers on improving their leadership skills. Every major HCM provider is now implementing algorithms, making it important for organizations to maintain accurate data and carefully review these tools for accuracy.

The use of HR data for analysis, forecasting and productivity gains in practice has increased dramatically. Organizations accumulate more personal and business data about their employees, and progressively use these technologies to automate existing HR processes.

World pioneers are radically rethinking processes dealing with HCM to maximize the value of employee data whereas in Ukraine these problems are not among the top priorities and the appropriate attention is not paid to these issues.

Ukraine has a high potential for HCM transformation. It is 24 th out of 130 countries in the global human capital rating (World Economic Forum, 2017). 73 percent of top managers believe that employee data takes an important role in making managerial decisions (Tutovska, 2018). Based on the fact, that 93 percent of organizations in the world plan to make significant organizational changes in the next 2 years, Ukrainian companies should step up the transition to new models for management support (Mercer, 2018). Moreover, in order to be competitive in the era of the information economy, it is not only necessary to develop an employee data analysis, but to create proactive HCM systems.

The use of employee data for analyzing, predicting and improving their performance has become incredibly popular. However, this is opportunities and risks at the same time. Organizations that accrue more and more information about employees face the risks and ethical issues related to the security and transparency of data, as well as the need to develop strategies to predict the threats of economic security of entrepreneurship. At the moment, organizations need powerful security and information policies to prevent employees from being disturbed by privacy. In addition, to avoid the possibilities of abuse by employers through the possibility of unauthorized use of information and technologies' transfer.

\section{Literature Review}

The publications dedicated to these problems relate to a number of areas, including the analysis of the predictive workforce analytics' implementation; the study of the analytical capabilities of information systems (IS) for HCM; the use of various model approaches and tools, and the study of business data security issues.

Based on Bersin's talent analytics maturity model (Bersin, 2012), there are several maturity levels of workforce analytics (WFA): operational reporting, advanced reporting, strategic analytics, and predictive analytics which is considered to be the highest level. Concurrently, Cascio and Boudreau (2015) argued that a wall between descriptive and predictive analytics should be destroyed by the relevant analytical tools and professionals. According to research results of Deloitte (2018), "69 percent of organizations are building integrated systems to analyze employee-related data, and 17 percent already have real-time dashboards to crunch the avalanche of numbers in new and useful ways. Among companies at level 3 and 4 in Bersin's talent analytics maturity model, 90 percent 
have accurate, timely data, and 95 percent have data security policies in place. These leading companies are monitoring people data from many sources, including social media $(17 \%)$, surveys $(76 \%)$, and integrated data from HCM and financial systems $(87 \%)$ ") (p. 89-90).

By means of advanced analytics, it became possible to control and analyze a large amount of employee data, including voice, personal interactions, and video interviews. This area belongs to organizational network analysis software that interprets email and social media traffic to monitor employees stress level and helps identify fraud, poor management, etc. (Blokdyk, 2018).

The effects of information systems in HCM were discussed in (Silva \& Lima, 2018). The same study analyzed the existing literature on the topic and described the benefits and possible limitations of IS using. According to Silva and Lima (2018), "HRIS (Human Resource Information System, authors' note) is a management system designed specifically to provide managers with information to make HR decisions. Is a system that lets you keep track of all your employees and information about them" (p.115). The next-generation HRIS (Talent Management Systems, particularly) are usually provided with powerful WFA modules, the features of which are presented, for instance, in (Kavanagh, Thite, \& Johnson, 2017). Some studies compare the capabilities of different IS which can support WFA. Thus, Behzad (2013) implemented the comparison of SAP analytical software for WFA.

Lots of the researchers found that most of the models and algorithms behind WFA tools offer such features as automating the collection of data from multiple sources and verify the quality of the data; using standard HR metrics to explain data; presenting information in appealing formats, specifically dashboards and personalized reports; using predefined indicators to monitor continuous performance management data (Kavanagh et al, 2017; Hughes, 2018). However, nowadays great importance for WFA is acquired the models of predictive analytics. The practice of using predictive analytics is revealed in many studies (Isson \& Harriott, 2016; Marr, 2018; Soundararajan \& Singh, 2019).

Research by Soundararajan and Singh (2019) supports that models for predicting employee behavior take a key place among the models of predictive WFA. This is particularly so with forecasting possible attrition of employees. There are plenty of examples of using predictive analytics models to solve this problem (Saravakos \& Sirakoulis, 2014; Rohit \& Ajit, 2016; Zhu, 2016).

Davidson (2012) noted that the use of employee data to model and the use of the results of analytics involved in a number of risks for entrepreneurship. Relevant issues are significantly related to the information security problem, which is one of the most important parts of economic security of entrepreneurship (Popkova, Khmeleva, \& Ostrovskiy, 2015). The most up-to-date research on information security include such relevant topics as endpoint security, ethical hacking, communications security, social engineering, cloud security, penetration testing and much more (Vacca, 2017).

Consequently, the analysis of relevant scientific studies confirms that predictive analytics and computational intelligence will bring transformative change to HCM. Ukrainian companies simply cannot thrive without taking advantage of the best and state-of-the-art technology. That is why, the actual research topics, which are not sufficiently disclosed in scientific publications, as are the comparison of trends in the implementation of 
predictive WFA in the world and in Ukraine, predictive analytics and a proactive approach to HCM, models of IS integration in order to provide maximum functionality, accessibility for implementation and ensuring security of entrepreneurship.

The main purpose of this paper is to inquire into the problems of implementing a predictive HR analytics for effective HCM in the world and in Ukraine in the context of a proactive approach to management; offer effective configurations of the appropriate software to support proactive HCM. Most of the focus is put on the issues of realization processes of forecasting the employee behavior based on effective integration of various information and analytics systems. Special attention is paid to security of the business data and using it in the peaceful and legal aims.

The remaining part of the paper is organized in three sections. Section 2 is a brief overview of materials relating to the comparison of trends in the implementation of predictive WFA in the world and in Ukraine, the need to protect business data for security of entrepreneurship, the task of predictive analysis in the context of proactive HCM and the methodology used in the study to develop models for integration and comparison of the obtained systems. Section 3 outlines the research results, namely, integration models, their comparison and an example of implementation. A summary and takeaways conclude the paper in Conclusions.

\section{Materials and Methodology}

The object of WFA is basically "recruitment, staffing, training and development, personnel, and compensation and benefits, as well as standard ratios that consist of time to fill, cost per hire, accession rate, retention rate, replacement rate, add rate, time to start and offer acceptance rate" ("Workforce Analytics", n.d.). To achieve the required results, the main instruments are "powerful analytics solutions backed by data science and machine learning for managing and fostering talent, helping them make more objective decisions while saving cost and time" (ibid).

The world is waiting for explosive growth for smart products that leverage employee data. Unfortunately, in Ukraine such technologies are only gaining application in the workplace (Ablitsova, 2018; Tutovska, 2018).

Comparison of the characteristics, which illustrate the organization's current capabilities to improve the HR solutions performance in the world and in Ukraine, demonstrates the domination of basic reporting on progressive reporting and progressive analysis in Ukraine, while in the world conversely (see Figure 1).

Most (91\%) HR leaders in Ukraine cite roadblocks such as a lack of integration among data systems and a lack of management experience in effectively using analytics (Tutovska, 2018). The data that answers some of the most thought-provoking talent questions cannot be found in the HCM system, but in marketing and financial management systems.

As it becomes easier to gather data from internal IS, organizations are analyzing their social networks, along with activity data, for insight into the quality of informal structures, sentiments across the company, and the return on these networks. Mining data across the network from their ecosystem (suppliers, partners, and customers) adds to the dynamic picture of how organizations work in practice and what levers might 
most improve effectiveness. At the same time, risks and ethical questions about data security are becoming more and more important (Deloitte, 2018).

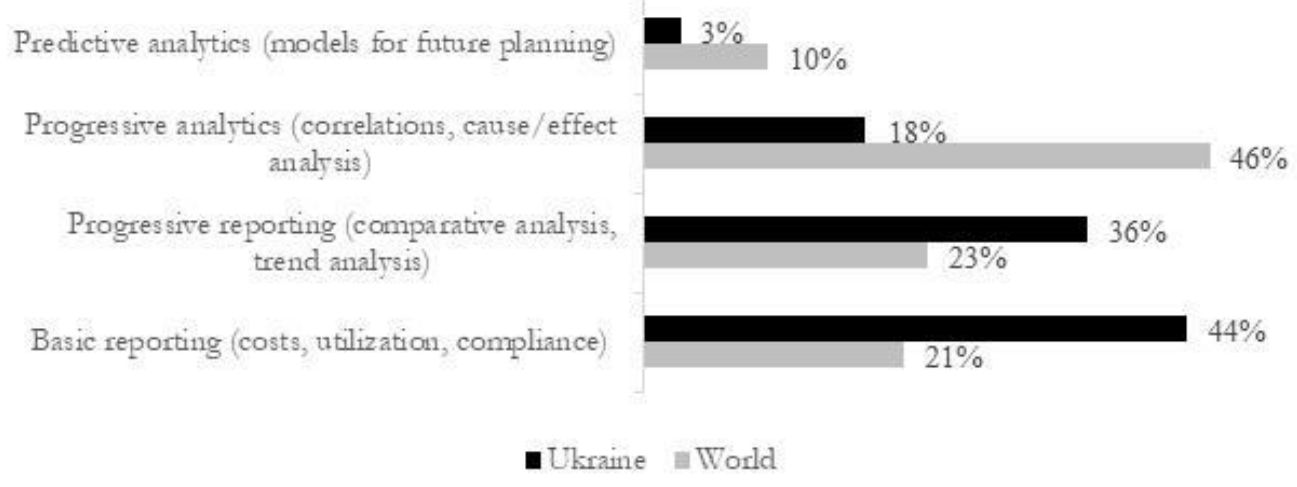

Figure 1. The current organization's ability to analyze employee data

Source: Deloitte Touche, 2018; Mercer, 2018

Human capital is one of the decisive factors of competitiveness. It means that, who can capture the information about human resources provoke a threat to the economic security of entrepreneurship. That is why it is necessary to ensure the effective management of all spectrum of risks associated with the collection, storage and use of data.

According to (Deloitte, 2018), there are some important factors which influence at employee data breach: legal liability (64\%); employee perception of personal data use $(60 \%)$; employment brand (46\%); financial cost (42\%); competitive risk (34\%); consumer brand $(25 \%)$.

Such results show that security has a lot of various features with different importance. The first place belongs to the juridical side. It means that strong legal aspects protect employees and they feel safe and secure themselves. As a result, high employee perception of personal data use. Than other factors go with less level of percentage, but they present in the list. This survey reflects behavior of personnel at the corporate culture. If there are social responsibility and corporate values in the company the positive reputation is created inside and out of the company. At the same time, such situation causes the formation of security system of personal data.

The level of personal data protection of the company's employees in Ukraine and in the world is also different. We can see it in Figure 2. This is a vital reason to pay special attention to the need for the introduction of powerful information security systems. 


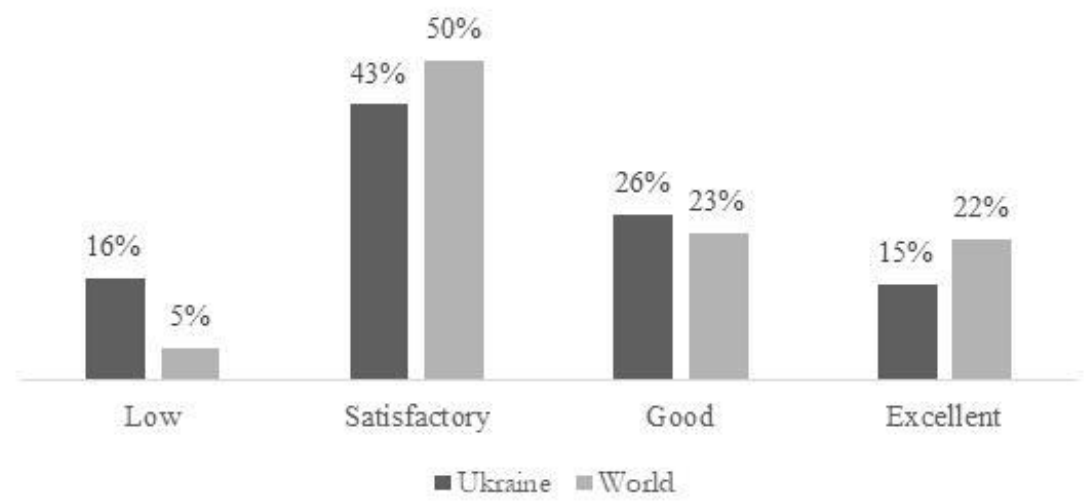

Figure 2. Assessment of the organizations' personal data protection system

Source: Deloitte Touche, 2018

The more level of security of employee data exists in the company the more competitive advantages it has. There is the direct dependence between company's development and its data security system. It means that the top management understands the modern threats and potential risks of illegal transfer of personnel data and the company's information. Creation of cybersecurity department and exploitation of relevant IS prevent the majority of existing challenges of information leak.

Large software vendors provide a wide range of information security tools that help organizations figure out what data should be protected, to get the secure access to this data, to ensure data encryption. Moreover, they guarantee that data confidentiality will be ensured throughout the life cycle of information. They propose to organizations the powerful and flexible real-time analysis, audit and reporting tools. These measures protect from future markets failures and promote further improvement of the company's reputation at the market and among employees.

Consequently, the need for the widest introduction of secure systems for HCM is a prerequisite in the contemporary business environment.

The next important issue for this research is the correlation of predictive WFA in general and employee behavior forecasting models, in particular, and the proactive approach to HCM.

Predictive analysis, as one of the forms of business forecasting, is central to proactive HCM.

Models for predicting employee behavior takes a key place in the predictive WFA and have a great importance for supporting decision-making under proactive HCM, both in general and at certain time intervals. Each of the predictive models supports decisionmaking on certain aspects of proactive HCM. The forecast of the probability of employee outflow provides an opportunity to select applicants in advance for possible vacancy positions in the near future or to formulate strategies for employee retention; the forecast of employee absence at the workplace ensures the timely preparation of the candidates' pool as well as the manpower gave the absence. The forecast of the employee productivity allows to determine the opportunities for his/her personal development, 
formulate plans corresponding to the capabilities of the employee, give an opportunity to evaluate the potential of his productivity at different positions in the organization.

The importance of implementing these and other models of predictive analytics for HCM leads to the fact that according to Deloitte' research (2018) "more than 70 percent of respondents are in the midst of major projects to analyze and integrate employee data into their decision-making" (p. 89).

However, different organizations have different capabilities to implement powerful WFA. Therefore, for the development of various effective IS configurations in this paper, methods of structural-functional analysis and synthesis, a comparative typological method are used. The evaluation of each proposed configuration was carried out according to the Analytics Value Chain (Ong, 2012). The idea of the approach of configurations comparing is similar to the idea presented in the research of Behzad (2013).

\section{Results}

WFA presents a composition of software and methodology that applies models of intelligent data analysis (IDA) to employee data, allowing top managers of organization to optimize HCM.

Large vendors that make enterprise software to manage business operations tend to place their WFA software within ERP systems or HCM suites. Some WFA products allow connecting such analytics with long-term operational plans via direct integration into business financial applications.

WFA is presented the most complete in the respective modules of HRIS. For instance, WFA of SAP SuccessFactors include built-in expertise in HR metrics (more than 2000) and access to the expert community. Among other powerful vendors of WFA software can be noted Visier, ADP, Oracle, Workday, Sage, etc.

However, this standardization does not always correspond to the specifics of a particular organization. In order to expand the capabilities of WFA significantly, methods of IDA need to be implemented, specifically Data Mining, Text Mining, OLAP.

For HCM tasks, IDA offers a wide range of models: statistical, tree-based solutions, neural networks, and various hybrids (Isson \& Harriott, 2016). Powerful technological support for the implementation of analytics processes is presented in the form of analytics platforms; databases with libraries of IAD algorithms; statistical packages with IAD capabilities and a large number of specialized packages.

Among the significant benefits of using specialized IAD software is the ability to justify input factors (HR metrics), a large number of models for experiments, the ability to build ensembles and other hybrid models, which in general greatly improves the quality of the analysis results, and hence the subsequent managerial data-driven decisions.

Verification of the factors influencing employee behavior is an extremely important and complicated task within WFA (Connor, 2016; Merriman, 2017; Marr, 2018; Edwards \& Edwards, 2019). HCM requires a lot of measurement and technical skill. With experienced data analysts, an organization can work with WFA at an advanced level, taking HR professionals through examples of particular predictive models so they can develop effective HR strategies based on evidence. 
In order to have up-to-date HR metrics, it is necessary to use IDA algorithms to analyze personal profile information regularly; learning which rewards, roles, and experiences drive outcomes and accelerate careers by mining HRIS data; understanding how the organization's purpose and values are resonating; charting talent movement and identify bottlenecks using Internal Labor Market maps (Parker, 2019).

When reviewing IS that may be valuable for WFA, the capabilities of Business Intelligence (BI) should be mentioned. BI systems include reporting tools, dashboards, as well as elements of advanced analytics, context analysis, process, text, and in-memory analytics. Such BI systems as SAP BusinessObjects, Oracle Hyperion Planning, IBM Planning Analytics, SAS BI will be useful for maintaining the reporting and visualization of WFA results.

Modern enterprises have developed IT infrastructure; their HCM is supported by ERP and HRIS. At the same time, the involvement of predictive analytics systems and BI into HCM processes helps to optimize the use of the potential of modern IS and, as the result, support comprehensive proactive HCM.

Therefore, in addition to using the 'HRIS + inlined module WFA' model, we can propose two variants of system configuration for proactive HCM.

The configuration I combines ERP, HRIS, BI, and Predictive Analytics systems (ERP+HRIS+BI+PA).

The configuration II combines ERP, HRIS with full-featured WFA, BI, and Predictive Analytics systems (HRIS+WFA+BI+PA).

The values of each type of the systems are presented in Table 1 and Table 2.

Table 1. The values of configuration I according to the Analytics Value Chain

\begin{tabular}{|c|c|c|c|}
\hline \multicolumn{2}{|c|}{$\begin{array}{l}\text { Elements of ERP, HRIS } \\
\text { the Chain }\end{array}$} & $\begin{array}{l}\text { Predictive Analytics } \\
\text { Systems }\end{array}$ & $\begin{array}{l}\text { Business Intelligence } \\
\text { (Business Warehouse) }\end{array}$ \\
\hline$\overline{\text { Data }}$ & Data source & Measuring data quality & $\begin{array}{l}\text { The data model basis (private data } \\
\text { warehouse, a standard business } \\
\text { warehouse) }\end{array}$ \\
\hline Metrics & & $\begin{array}{l}\text { Identifying the most } \\
\text { important predictors } \\
\text { (metrics) }\end{array}$ & $\begin{array}{l}\text { The basis for visualization using } \\
\text { dashboards (identifying KPIs; } \\
\text { building and rolling out the metrics) }\end{array}$ \\
\hline Analysis & $\begin{array}{l}\text { Quantitative and } \\
\text { qualitative } \\
\text { analysis }\end{array}$ & $\begin{array}{l}\text { Developing and } \\
\text { evaluation of predictive } \\
\text { models: standard and } \\
\text { hybrids }\end{array}$ & $\begin{array}{l}\text { OLAP (exploring and assessing data } \\
\text { visually, drilling down to identify the } \\
\text { root causes and confirm guesses } \\
\text { quickly) }\end{array}$ \\
\hline Insight & $\begin{array}{l}\text { Comprehensive } \\
\text { basic reporting }\end{array}$ & $\begin{array}{l}\text { Integration of simulation } \\
\text { results }\end{array}$ & $\begin{array}{l}\text { Visualization of the analysis results to } \\
\text { interpret this information; ad hoc } \\
\text { reporting }\end{array}$ \\
\hline Action & & $\begin{array}{l}\text { Implementation of } \\
\text { simulation results }\end{array}$ & $\begin{array}{l}\text { Visualization of the analysis results to } \\
\text { determine suitable actions }\end{array}$ \\
\hline
\end{tabular}

Source: Compiled by the authors

In all discovered cases, the integration with information security systems is mandatory. These systems can help solve a number of business problems, including: consolidating data warehouses into one integrated solution; detection of insider theft and fraud; 
vulnerability, configuration, compliance and risk management; conducting expert investigations of incidents and offenses.

Best fulfils this objective an intelligence platform. It builds on the threat intelligence expertise to provide a proactive approach to security, to keep the entire organization infrastructure, including the cloud, protected from the latest security risks. Information protection is carried out using automatic procedures that predict future events on the basis of historical data, as well as automatically adjust the monitoring parameters of events to a specific state of the system.

According to the Gartner, the following security software vendors among the leaders in 2018 are: Splunk, IBM and LogRhythm (Kavanagh, Bussa, \& Sadowski, 2018).

Table 2. The values of configuration II according to the Analytics Value Chain

\begin{tabular}{|c|c|c|c|}
\hline $\begin{array}{l}\text { Elements } \\
\text { of the } \\
\text { Chain }\end{array}$ & ERP, HRIS, WFA & $\begin{array}{l}\text { Predictive Analytics } \\
\text { Systems }\end{array}$ & $\begin{array}{l}\text { Business Intelligence } \\
\text { (Business Warehouse) }\end{array}$ \\
\hline Data & $\begin{array}{l}\text { Target maps, data source, } \\
\text { specialty warehouse }\end{array}$ & Measuring data quality & $\begin{array}{l}\text { The data model basis (private } \\
\text { data warehouse, a standard } \\
\text { business warehouse) }\end{array}$ \\
\hline Metrics & $\begin{array}{l}\text { Predefined metrics' library } \\
\text { directing attention at all } \\
\text { relevant topics }\end{array}$ & $\begin{array}{l}\text { Identifying the most } \\
\text { important predictors } \\
\text { (metrics) }\end{array}$ & $\begin{array}{l}\text { The basis for visualization } \\
\text { using dashboards (identifying } \\
\text { KPIs; building and rolling } \\
\text { out the metrics) }\end{array}$ \\
\hline Analysis & $\begin{array}{l}\text { Question-driven analytics } \\
\text { across HCM topics; query, } \\
\text { reporting, dashboards, basic } \\
\text { predictive modeling }\end{array}$ & $\begin{array}{l}\text { Developing and } \\
\text { evaluation of advanced } \\
\text { predictive models: } \\
\text { ensembles and hybrids }\end{array}$ & $\begin{array}{l}\text { OLAP (exploring and } \\
\text { assessing data visually, } \\
\text { drilling down to identify the } \\
\text { root causes and confirm } \\
\text { guesses quickly) }\end{array}$ \\
\hline Insight & $\begin{array}{l}\text { Finding problem issues that } \\
\text { are important for the } \\
\text { manager, and present alerts } \\
\text { to him in common language }\end{array}$ & $\begin{array}{l}\text { Integration of } \\
\text { simulation results }\end{array}$ & $\begin{array}{l}\text { Visualization of the analysis } \\
\text { results (the graphs, charts) to } \\
\text { interpret this information; } \\
\text { basic and ad hoc reporting; } \\
\text { automatic report distribution }\end{array}$ \\
\hline Action & $\begin{array}{l}\text { Recommendation for action } \\
\text { from the storage of the best } \\
\text { practice }\end{array}$ & $\begin{array}{l}\text { Implementation of } \\
\text { simulation results }\end{array}$ & $\begin{array}{l}\text { House-wide visualization of } \\
\text { the analysis results } \\
\text { (dashboards) to determine } \\
\text { suitable actions }\end{array}$ \\
\hline
\end{tabular}

Source: Compiled by the authors

Undoubtedly, each of the proposed configurations has its advantages and disadvantages and is optimal, under certain conditions.

The use of a particular HRIS and WFA module may be sufficient in the absence of the required number of IT technicians being able to integrate these systems and BI, as well as the lack of data analysts who need to develop and maintain relevant IDA models. Typically, such a configuration (HRIS + WFA) is used in large organizations with more than 5000 employees.

An extremely strong point of this model is its well-rounded inlined content, specially designed to meet the requirements of HR analytics. Moreover, HR and business 
managers can obtain strategic and tactical insight obtained from the WFA without becoming specialists in the field of data science or IT, as well as without exchanging indepth experience with their IT staff supporting the BI system.

The most important advantage is that WFA has the library of great number of predefined measures (metrics) which come with the clear definition, the formula for calculating, and its goal is to provide harmonized standard for all users. Such a knowledge base reflects best practices, covering all regions and industries, which allows HR specialists to learn from direct experience by easily using the relevant software.

Besides, these systems have built-in models to define what can contribute to the current condition, other related concepts to consider, proposals on how to respond to the situation, and predictive analytics models to determine who and what else might be at risk. WFA can realize comparative analysis between organizations using software solution.

At the same time, a set of predictive analytics models has limited built-in capabilities, which is a weak point in this approach.

Organizations with powerful analytic thinking can apply the might of configuration 'HRIS+PA+BI' to drive an advantage. However, these tools do not reflect the specifics of HR.

It is advisable to interview HR experts determine the metrics and share their in-depth experience with IT specialists supporting the BI setting. Next step, the complexity becomes the formation of specific analytical skills and expertise in the personnel division.

BI tools often cause current issues that are difficult to resolve promptly. They provide the convenience for creating the most complicated reports, multifarious dashboards, but sending them to the managers' devices, inducing further self-interpretation of the results. This once again confirms that the BI tools alone "are not smart enough to transform data into meaningful and useful information for business purposes without intervention from resources with expertise" (Behzad, 2013).

The same applies to the Predictive Analytics tools. These systems have a complete set of various IDA models, it can implement machine learning, and most importantly, they have the ability to build the most complex hybrid models and ensemble models. With experienced data analysts, it is possible to build relevant models for the organization and draw valuable insights from employee data.

Many of the WFA features can be reproduced on top of an organization BI and/or analytics platform, but it is associated great efforts and a very long period for implementation.

The most effective for large organizations is the configuration 'HRIS+WFA+BI+PA'. Moreover, it cannot be called very expensive compared to previous models. Large companies use BI and analytics systems for many purposes. Both the unified and complete BI system and the platform of predictive analytics cover the full range of BI and analytics problems across the organization. Such organizations also have powerful IT resources, a sufficient number of data analysts.

In simultaneous deployment (WFA, Predictive Analytics, BI), we can expand the use of HR metrics from WFA by allowing amalgamation with inter-organization reports that will be presented through the organization's scorecards and dashboards to increase the 
visibility of workforce trends, dangers and prospects. This can help speed up the comparison and analysis of workforce characteristics with information from other organization units, as well as gain insight into how talent investments affect business results.

The comparative characteristic of the proposed configurations is presented in Table 3. All configurations involve applying of Security Intelligence Platform (SIP), which delivers security and compliance advantages that possess an immeasurable value on Big Data environment.

The proposed approach (configuration 'HRIS+PA+BI') was implemented to analyze the employee attrition in the pharmaceutical company of Ukraine. The database of employees included 7,000 people. In addition, some data were collected from other companies in this industry was also involved. The company has a powerful IT infrastructure. The transition to cloud-based Talent Management System SAP Success Factor in the area of HCM is being carried out. It simplified the data gathering and formation of the employee profiles.

The integration of relevant IS has been implemented on the basis of a proactive HCM approach which involves the actualization of processes, including situation review, causal analysis, decision-making and predictive analysis. Powered by this, support for employee attrition management has included a number of tasks implemented on the basis of relevant tools (Table 4 ).

The main analytics systems used in the enterprise are IBM products, namely SPSS Modeler and Planning Analytics. Planning Analytics includes Cognos Analytics as a complex BI tool, as well as an ad-hoc tool - Watson Analytics.

To combat the problem of employee attrition, the following actions were taken:

1) Creating the open database that accumulates, processes, cleans employee data and links it to the Data Mining, Business Intelligence, planning, and ad-hoc analysis systems; 2) Identification of the factors that have an impact on employee behavior and their desire to stay in the organization. A quantitative and qualitative analysis based on SPSS Modeler;

3) Data Mining modeling for binary classification of employees on a number of selected attributes in SPSS Modeler based on a hybrid model in the form of ensemble (SVM, neural network (boosting) and C5.0 classification) with sequential weighing based on overall accuracy (periods: a month, a quarter, half a year, a year);

4) Data Mining modeling for evaluation of the probability of employee attrition (decision trees), forecasting the time before employee attrition through survival analysis (Cox regression); forecasting indicators of personal effectiveness of employees by individual categories of employees, by different age groups, etc.;

5) Linking database and Data Mining results with OLAP cubes of IBM Planning Analytics to use operational costs in planning, monitoring KPI, planning resources in the organization;

6) The implementation of dashboards and reporting automation through the portfolio components of Planning Analytics, which are Cognos and Watson Analytics;

7) Ad-hoc analysis and rapid construction of the decision tree and impact helix in Watson Analytics. 
Table 3. The comparative characteristic of the IS configurations

\begin{tabular}{|c|c|c|c|}
\hline \multirow[t]{2}{*}{ Characteristics } & \multicolumn{3}{|l|}{ Configurations } \\
\hline & SIP+HRIS+WFA & SIP+HRIS+PA+BI & SIP+HRIS+WFA+PA+BI \\
\hline $\begin{array}{l}\text { Data and data } \\
\text { warehouse }\end{array}$ & $\begin{array}{l}\text { Specialized data } \\
\text { warehouse optimized for } \\
\text { HR-related data sources } \\
\text { and metrics }\end{array}$ & $\begin{array}{l}\text { Private data warehouse, a } \\
\text { standard business } \\
\text { warehouse, third party one }\end{array}$ & $\begin{array}{l}\text { Any warehouse as the data model } \\
\text { basis with its subsequent expansion } \\
\text { to meet diverse needs }\end{array}$ \\
\hline $\begin{array}{l}\text { Requirement } \\
\text { of IT } \\
\text { professionals }\end{array}$ & $\begin{array}{l}\text { No need for bringing } \\
\text { expertise on data and IT. } \\
\text { The software is intuitive } \\
\text { and destined for } \\
\text { professionals in the field } \\
\text { of HR and business users }\end{array}$ & $\begin{array}{l}\text { A large number of IT } \\
\text { professionals in IDA } \\
\text { technology are required to } \\
\text { support HR in reporting } \\
\text { and output, advanced } \\
\text { predictive modeling }\end{array}$ & $\begin{array}{l}\text { A certain quantity of IT } \\
\text { professionals in IDA technology } \\
\text { are required to enhance inlined } \\
\text { capabilities of analysis, generating } \\
\text { of reports and output }\end{array}$ \\
\hline Functionality & $\begin{array}{l}\text { A specially designed } \\
\text { application delivering in- } \\
\text { depth and wide inlined } \\
\text { content to aim WFA } \\
\text { requirements specifically }\end{array}$ & $\begin{array}{l}\text { A multi-purpose BI tool set } \\
\text { which can embrace } \\
\text { workforce and other fields, } \\
\text { but all content and } \\
\text { advanced analysis must be } \\
\text { organize from the jump }\end{array}$ & $\begin{array}{l}\text { A multi-purpose application which } \\
\text { can cover HR and other fields, } \\
\text { delivering advanced WFA through } \\
\text { the prism of the entire organization }\end{array}$ \\
\hline Tools & $\begin{array}{l}\text { Inlined tools for } \\
\text { reporting, querying, } \\
\text { dashboarding, discovery, } \\
\text { exploration, basic } \\
\text { predictive analytics }\end{array}$ & $\begin{array}{l}\text { BI and advanced analytics } \\
\text { tools including ETL, } \\
\text { queries, reports, } \\
\text { dashboards, and advanced } \\
\text { predictive models }\end{array}$ & $\begin{array}{l}\text { Composed of advanced BI and } \\
\text { analytics tools to meet WFA } \\
\text { requirements specifically including } \\
\text { ad hoc reporting, and advanced } \\
\text { predictive modeling }\end{array}$ \\
\hline $\begin{array}{l}\text { Configuration } \\
\text { flexibility }\end{array}$ & $\begin{array}{l}\text { Flexibility that allows } \\
\text { users from HR and } \\
\text { related fields to quickly } \\
\text { identify and perform } \\
\text { specific employee-related } \\
\text { metrics }\end{array}$ & $\begin{array}{l}\text { Very power-packed and } \\
\text { flexible in sense of using } \\
\text { throughout the organization }\end{array}$ & $\begin{array}{l}\text { Very power-packed and flexible in } \\
\text { sense of how the suite is configured } \\
\text { and installed by IT team for use } \\
\text { throughout the organization }\end{array}$ \\
\hline Setup time & $\begin{array}{l}\text { After loading data, the } \\
\text { software is ready } \\
\text { immediately to use and } \\
\text { draw valuable insights }\end{array}$ & $\begin{array}{l}\text { Except data formation, } \\
\text { efforts must be stepped up } \\
\text { for developing queries, } \\
\text { metrics, dashboards using } \\
\text { the appropriate advanced } \\
\text { analytics software }\end{array}$ & $\begin{array}{l}\text { The tool set is ready to solve the } \\
\text { main challenges immediately, and } \\
\text { then expanding its capability to } \\
\text { meet diverse advanced needs using } \\
\text { IDA models, ad hoc instruments, } \\
\text { etc. }\end{array}$ \\
\hline $\begin{array}{l}\text { The primary } \\
\text { objective of } \\
\text { tool set }\end{array}$ & $\begin{array}{l}\text { Help for users from HR } \\
\text { and related fields to } \\
\text { upgrade skills and learn } \\
\text { how to use analytics to } \\
\text { make proactive HR } \\
\text { decisions }\end{array}$ & $\begin{array}{l}\text { Help for chosen advanced } \\
\text { users from HR and IT } \\
\text { technicians to apply } \\
\text { analytics for better data- } \\
\text { driven decisions, upgrade } \\
\text { skills and learn intelligent } \\
\text { data analysis }\end{array}$ & $\begin{array}{l}\text { Help for users from HR and related } \\
\text { fields, IT and data professionals to } \\
\text { upgrade skills and learn new } \\
\text { technologies, to apply analytics for } \\
\text { proactive data-driven HR decisions }\end{array}$ \\
\hline
\end{tabular}

Source: Compiled by the authors

All presented systems are integrated with the IBM QRadar Security Intelligence Platform, an information security support platform that integrates hardware, software and services. This platform is simple to deploy and manage, offering extensive integration modules and security intelligence content. 
Table 4. Challenges and information support for attrition management

\begin{tabular}{ll}
\hline Challenge & Information systems for support \\
\hline Accumulation of employee data and profiling & ERP Systems, HRIS, Social Media \\
Insight of the present state of employees and team & HRIS, Business Intelligence \\
Vision of the future state of employees and team & Predictive Analytics Systems, Business \\
& Intelligence \\
Cause-and-effect forecasting of employee & Ad-Hoc Analytics Systems, Business \\
behavior, what-if analysis & Intelligence \\
\hline Source: Compiled by the authors &
\end{tabular}

The interaction between the processes and systems that support them is presented in Figure 3.

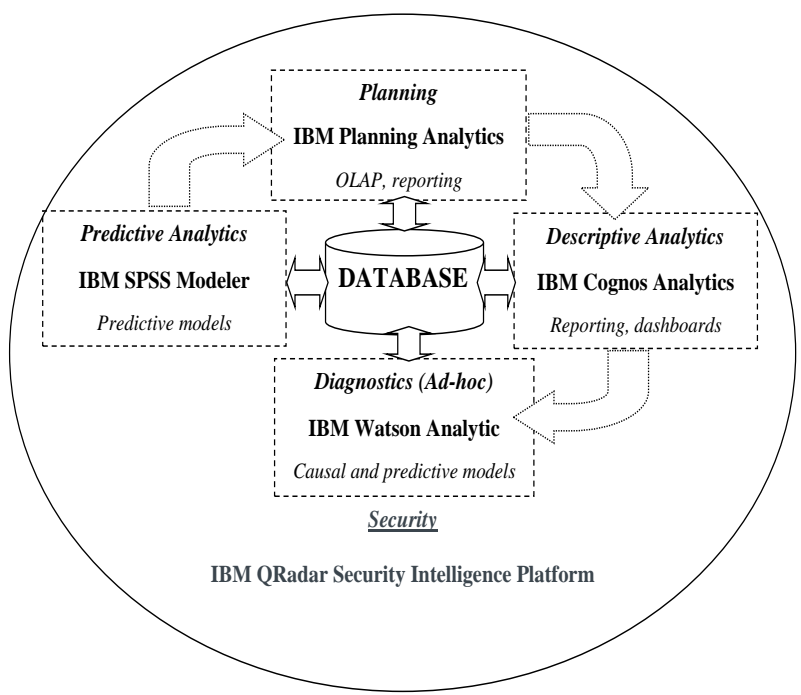

Figure 3. Information interaction in forecasting the employee attrition

Source: Compiled by the authors

The implementation of the results of predictive models' realization enabled to determine the best ways for motivation and measures for employee retention (at the level of individuals); staffing level planning, taking into account the risk of resignation or reduction of productivity (at the level of the separate division); determination of the optimal staffing level, top performing employees and teams (at the level of the business process). These results were achieved not only due to the use of WFA methods but also through the optimal IS integration available in the company, which made it possible to significantly improve comprehension of managers at all levels and provided them with the necessary information for making rational and timely decisions.

The presented results induce the feasibility of software integration projects development, the creation of options to maximize the usage of all available IS and software to achieve synergy effect, and as a consequence to improve the organization's performance. 


\section{Conclusions}

The findings presented in the paper show a wide range of possibilities for the implementation of predictive WFA. Each organization can choose a specific combination of IS and technologies based on the cost of developing and ownership of such complexes. The main idea of the attained results is that solving the problem of introducing new analytics tools should always be considered through the prism of promising models of IS integration in order to obtain the maximum effect from the use of the existing IT potential of the organization. Naturally, there are some restrictions of WFA for small organizations due to quite expensive HCM implementation.

Moreover, organizations today are exposed to a greater volume and variety of attacks than in the past. Advanced attackers are clever and patient, that is why it is imperative to use software, which helps detect and defend against threats by applying sophisticated analytics to more types of data. Modern security platforms are also intuitive and flexible enough for small and midsize organizations. Users benefit from potentially faster time to value, lower cost of ownership, greater agility, and enhanced protection against security and compliance risks.

An important result of large-scale implementation of proposed advanced WFA models is subjectivity avoidance HCM decision-making, substantiation of the effective decisions based on knowledge extracted through the employee data mining.

The problem is that there are many scientific findings that have been available for a long time but hardly used in organizations.

Besides, should be kept in mind that the expectations of WFA are often too high. Indeed, human behavior is not so easy to predict, even if you have access to loads of people data. Besides, it is important to remember that managers, employees and HR professionals don't always behave in a rational way. All people are prone to cognitive biases that influence the way they interpret the outcomes of WFA (Haak, 2017).

In spite of these biases, as more organizations rush to embrace new technologies, the marketplace for predictive WFA is booming.

Ukrainian business has also understanding of the imperative of the HCM transformation processes. But the complicated problem is maturity of the organization in the sense of having the tools for protected advanced analytics and IT staff for supporting the analytics.

Ukrainian companies need to actively involve relevant professionals in HCM transformation projects. Generally, the highest level is predictive analytics. In order not to ignore the learning curve, the transformation must be gradual. Here the integration of HCM software and available general-purpose information and analytics systems will be of great importance to maximize the effect of their use as presented in this paper. It does not mean that organizations must implement advanced analytics and the most powerful IS immediately, but at least they can start using MS Excel capabilities ( $\mathrm{Ng}$ Mong Shen, 2018).

The HCM transformation, based on prediction analytics and effective IS integration, having a powerful information protection system, offers many benefits: less routine, advanced analytics, convenient processes (for HCM); transparency, self-service, intuitive 
interface (for employees); acceleration, productivity, competitiveness (for an organization).

Digitalization penetrates all fields of activities, dictates serious requirements for economic security of entrepreneurship. The most important one is the information security of both enterprise data and employees' personal information. The second requirement is the creation of strong corporate culture, because it forms the company's reputation as the strong competitive advantage in the society. As the result, the correct reputation management with the strategic view guarantees the protection of company and its clients, which means the powerful social responsibility.

Every organization that is eager to be competitive in the era of digitalization should develop its HCM strategy and concentrate on employee behavior observation starting with effective implementation of predictive analytics models and optimal IS integration and data protection. Moreover, it has to realize that the objective is to build the integral protected proactive management system for HR and organization.

\section{Acknowledgement}

The research is done in the framework of STCU (Science and Technology Center in Ukraine, http://www.stcu.int/) project 9606 "Master program Economic Security of Entrepreneurship", which has started from March 1, 2019 at Taras Shevchenko National University of Kyiv (Ukraine) in cooperation with the Faculty of Economics.

\section{References}

Ablitsova, A. (2018, June 14). HR trendy 2018. Chym Ukrayina vidriznyayetsya vid svitu [HR Trends 2018 : How Ukraine is Different from the World]. Retrieved from https://kfund-media.com/hr-trendy2018-chym-ukrayina-vidriznyayetsya-vid-svitu/

Behzad, K. (2013, May 10). SuccessFactors Workforce Analytics or SAP Business Intelligence for Human Resources? Retrieved from https://blogs.sap.com/2013/05/10/successfactors-workforceanalytics-or-sap-business-intelligence-for-human-resources/

Bersin, J. (2012, November 24). Big Data in HR. Creating a New Science of Human Resources. Bersin \& Associates. Retrieved from https://www.slideshare.net/ibersin/bigdata-in-human-resourcesmaking-it-happen/36-Talent Analytics Maturity Model Level

Blokdyk, G. (2018). Organizational network analysis: Standard Requirements. North Charleston: CreateSpace Independent Publishing Platform.

Cascio, W., \& Boudreau, J. (2015). Investing in People: Financial Impact of Human Resource Initiatives. New Jersey: FT Press.

Connor, R.J. (2016). Organisational and Workforce Analytics. [Kindle Paperwhite version]. Retrieved from Amazon.com.

Davidson, M.A. (2012, October 2). Managing Risk across the Enterprise. Retrieved from: http:// www.securitymanagement.com/article/managing-risk-acrossthe-enterprise-005823.

Deloitte Touche. (2018). Employee Data. Trend Number 10. Retrieved from https://www2.deloitte.com/content/dam/Deloitte/ua/Documents/human-capital/DeloitteGlobal-Human-Capital-Trends-2018-Statistics-by-Ukraine-10.pdf

Deloitte. (2018). The Rise of the Social Enterprise. 2018 Deloitte Global Human Capital Trends. Retrieved from https://www2.deloitte.com/content/dam/Deloitte/at/Documents/human-capital/at-2018deloitte-human-capital-trends.pdf

Edwards, M.R., \& Edwards, K. (2019). Predictive HR Analytics: Mastering the HR Metric. London: Kogan Page. 
Haak, T. (2017, November 2). The Psychology of People Analytics. Retrieved from https://hrtrendinstitute.com/2017/11/02/psychology-people-analytics-video/

Hughes, R.C. (2018). Human Capital Systems, Analytics, and Data Mining. Boca Raton: Chapman and Hall/CRC. Isson, J.P., \& Harriott, J.S. (2016). People Analytics in the Era of Big Data: Changing the Way You Attract, Acquire, Develop, and Retain Talent. New Jersey: John Wiley \& Sons, Inc.

Kavanagh, K., Bussa T., \& Sadowski G. (2018). Magic Quadrant for Security Information and Event Management. Gartner.

Kavanagh, M. J., Thite M., \& Johnson, R.D. (2017). Human Resource Information Systems: Basics, Applications, and Future Directions. Los Angeles: SAGE Publications, Inc.

Marr, B. (2018). Data-Driven HR: How to Use Analytics and Metrics to Drive Performance. London: Kogan Page.

Mercer. (2018). Unlocking Growth in the Human Age. Mercer Global Talent Trends Study 2018. Retrieved from https://www.mercer.com/content/dam/mercer/attachments/global/webcasts/gl-2018-pdfglobal-talent-trends-study-us-canada.pdf

Merriman, K.K. (2017). Valuation of Human Capital: Quantifying the Importance of an Assembled Workforce. Basingstoke: Palgrave Macmillan.

Ng Mong Shen, C. (2018). Predictive HR Analytics. Singapore: Independently published.

Ong, B. (2012). Case Studies by the Google People Analytics Team. Retrieved from: http://www.hci.org/lib/casestudies-google-people-analytics-team.

Parker, P.M. (2019). The 2020-2025 World Outlook for Workforce Analytics. San Diego: ICON Group International, Inc.

Popkova, E.G., Khmeleva, G.A., \& Ostrovskiy, V.I. (2015). Innovative approach to providing economic security. Actual Problems of Economics, 169(7), 99-105.

Rohit, P., \& Ajit, P. (2016). Prediction of Employee Turnover in Organizations using Machine Learning Algorithms. International Journal of Advanced Research in Artificial Intelligence, 5(9), 22-26. doi: 10.14569/IJARAI.2016.050904

Soundararajan, R., \& Singh, K. (2019). Winning on HR Analytics: Leveraging Data for Competitive Advantage. Los Angeles: SAGE Publications Pvt. Ltd.

Saravakos, P., \& Sirakoulis, G.Ch. (2014). Modeling Employees Behavior in Workplace Dynamics. Journal of Computational Science, 5(5), 821-833. doi: 10.1016/j.jocs.2014.05.001

Silva, M. S. A. e, \& Lima, C. G. da S. (2018). "The Role of Information Systems in Human Resource Management”, Maria Pomffyova M. (Ed.) Management of Information Systems, IntechOpen, pp. 111126. doi: $10.5772 /$ intechopen.79294.

Tutovska, S. (2018, June 7). Tendencii' u sferi upravlinnja personalom - 2018. Mizhnarodne doslidzhennja Deloitte [Trends in HR Management - 2018. Deloitte International Survey]. Retrieved from https://www2.deloitte.com/ua/uk/pages/human-capital/articles/human-capital-trends-2018.html.

Vacca, J.R. (2017). Computer and Information Security. Morgan Kaufmann

Workforce Analytics. (n.d.). Retrieved from https://www.cornerstoneondemand.com/glossary/workforce$\underline{\text { analytics }}$

World Economic Forum. (2017). Preparing people for the future of work The Global Human Capital Report. Cologny/Geneva Switzerland.

Zhu, X. (2016). Forecasting Employee Turnover in Large Organizations. PhD diss., University of Tennessee. Retrieved from https://trace.tennessee.edu/utk graddiss/3985 